\title{
On the Biology of Poronia punctata (L.).
}

\author{
BY
}

MARIA DAWSON, B.Sc. (London and Wales),

I85I Exhibition Science Research Scholar.

\section{With Plates XIV and XV.}

$\mathrm{T}$

HE genus Poronia was founded by Willdenow ${ }^{1}$ in 1787 , and up to $\mathrm{I} 882$ it is given by Saccardo ${ }^{2}$ as containing seven species. In Lindau's ${ }^{3}$ classification eleven species are described.

The species here concerned was first described by Linnaeus.

$\mathrm{Up}$ to the present time but few investigators appear to have devoted their attention to Poronia. With the exception of a brief description of the external features of Poronia punctata, with excellent figures of the stromata, asci, and spores by Tulasne ${ }^{4}$, and a similar description, with an account of the cultivation of its spores and conidia-bearing stromata by Brefeld ${ }^{5}$, a mere passing reference is made to this Fungus in various contributions to our knowledge of the Ascomycetes.

${ }^{1}$ Willdenow, Flor. Berol. Prodr., p. 400.

${ }^{2}$ Saccardo, Sylloge Fung., vol. i, p. 348.

${ }^{3}$ See Engler and Prantl, Pflanzenfamilien, vol. i, Abt. i, p. 490.

4 Tulasne, Carpologia, ii, p. 27, tab. III.

5 Brefeld, Untersuch. a. d. Gesammtgebiet d. Mykologie, Heft x, p. 26r.

[Annals of Botany, Vo1. XIV. No. LIV. June, 1900.] 
It is usually cited as another example of the type of lifehistory exemplified by Xylaria, or as a member of the group Xylarieae, forming characteristic stromata, with one definite type of conidia, followed later by perithecia with asci and ascospores ${ }^{1}$.

A rough examination of the Fungus was sufficient to show that, in common with other members of its group, it offers many very interesting points for investigation; accordingly, at the suggestion of Professor Marshall Ward, to whom my thanks are due for many suggestions throughout the work, I undertook a somewhat detailed study of the species Poronia punctata, in November, I899. For the material on which the work was carried out I am indebted to Dr. Plowright, who collected it in the neighbourhood of King's Lynn, Norfolk.

\section{LIFE-HISTORY.}

Poronia punctata is an Ascomycetous Fungus, growing upon horse-dung, and characterized by its pegtop-shaped stromata with a whitish disk-like upper surface, mounted upon an unbranched stalk, rarely more than $\mathrm{I} \mathrm{cm}$. in height, and either standing erect above the surface of the substratum, or, as frequently happens, embedded within the substratum, so that only the expanded disk-shaped head is exposed to view (Plate XIV, Figs. I and 2).

In the earlier stages of development the upper parts of the stromata are covered with a greyish white powder, the conidia ; these are followed by black spots, scattered over the flat surface of the disk. These spots are the ostioles of the perithecia, which are embedded in the uppermost layers of the stromata, an arrangement which led Berkeley ${ }^{2}$ to draw attention to the superficial resemblance of these stromata to the antheridiophores of Marchantia. When the asci are

1 E.g. Fuisting, Bot. Ztg., 1867-68; Cornu, Ann. d. Sci. Nat. (Bot.), sér. vi, I876; De Bary, Comp. Morph. Fungi and Mycet., p. 244 ; Zopf, Die Pilze, I89o; Von Tavel, Vergl. Morph. d. Pilze, p. 92:

${ }^{2}$ Berkeley, Introd. to Crypt. Bot., I857, p. $44 \mathrm{I}$. 
quite ripe they protrude above the surface in minute black pillar-like masses, enclosing numerous ascospores. A longitudinal section of a mature stroma shows the perithecia in various stages of development, embedded in the vegetative portion of the stroma-head. Immature perithecia appear as more or less spherical dark patches at different levels below the surface, mature perithecia as flask-shaped bodies, opening on the surface (Plate XV, Fig. I6), and bounded by a very definite wall. The asci are club-shaped, and enclose eight dark brown ascospores, ellipsoidal in form, and having a lateral slit-like pit in the outer wall (Fig. 33). They measure 22 by $10 \mu$.

Among the asci are numerous colourless, long, slender, multicellular paraphyses. The conidia are small colourless pear-shaped bodies, with oil-like drops, and are formed by abstriction from the ends and sides of the terminal hyphae of a stroma. In some cases the stromata do not expand above into a disk-shaped head, but remain columnar in shape, in which case conidia only are formed, and there is no trace of perithecia (cf. Fig. 3).

For the purposes of pure cultures of the Fungus, groups of ascospores were collected from ripe perithecia by inverting the head of a stroma upon a sterile coverglass, on which it deposited numerous spores overnight. These were washed into a tube of sterile water, and thence plate- and hanging-drop cultures were made, in a medium consisting of 10 per cent. gelatine with a decoction of horse-dung.

For similar cultures of conidia, abundant material could be obtained from any young stroma. In this medium both kinds of spores germinated readily, at the ordinary temperatures of the laboratory $\left(15^{\circ}-20^{\circ} \mathrm{C}\right.$.).

The Ascospores form a lateral germ-tube, growing out through the slit-like pit of the exosporium; the germ-tubes are broad, with frequent septa, and the cells are filled with abundant vacuolated protoplasm. Lateral branches arise from points just below a septum, and, as a rule, alternately from left to right of the main hypha. Before definite 
elongation of the apex of a hypha, a marked constriction of the extreme end is noticeable, forming a kind of bud, and after considerable elongation of the bud-like protuberance a septum forms at the point of constriction (Fig. I $3 a-h$ ).

After twenty-four hours' growth frequent lateral anastomoses are seen in the young mycelium (Fig. $15 a, b$ ), also the exudation of glistening drops-possibly containing a ferment-like substance-from the tips of the hyphae.

The Conidia form germ-tubes from either end or from both ends simultaneously; occasionally three or four germ-tubes may arise from one spore (Figs. II and I2). The mycelium produced consists of branched and septate hyphae, at first very slender, but gradually becoming stronger, and eventually indistinguishable from the mycelium grown from an ascospore ${ }^{1}$.

If a young mycelium (grown either from a conidium or an ascospore) be transferred to a tube of horse-dung extract in gelatine or agar, in about three days a beautiful stellate growth is seen, consisting of radiating and glistening silky hyphae; after twelve to fourteen days central heaped-up masses become noticeable, and in three weeks' time minute pillar-like structures, standing up from the surface in the manner shown in Fig. $3 a$. A large number of young stromata of this kind have been cultivated, and from these have grown in great abundance stromata of unusually large size, frequently branched, and having the various forms found in nature, also bearing large numbers of conidia on the upper parts. Thus far, only early stages in the formation of perithecia have been found; further reference will be made to these later.

In Figures 3 and 4, sketches of some of these stromata, made at different stages in their development, are shown. These cultures have brought to notice several interesting points in the biology of the Fungus. From an examination of a very young stage (see Fig. $3 a$ ) we find that this consists entirely of vegetative hyphae, densely interwoven, and rising

${ }^{1}$ Early stages in the germination of ascospores and conidia were figured by Tulasne, loc. cit., tab. III. 
vertically from the surface of the horizontal mycelium, which has grown upon and within the substratum. This stage is shown under a low-power objective in Fig. 8, in which must also be noted the presence of numerous crystals of calcium oxalate, which have been separated from the substratum (Fig. 9). Similar crystals were also found in hanging-drop cultures about eleven days after infection (Fig. I0).

When the stromata have reached about half an inch in height they begin to expand at the top, and in some cases become considerably branched; in others, and this is the commoner case, the head continues to enlarge gradually into the form of an inverted cone or pegtop, and a flattish disk or cup-shaped surface is formed above, exactly comparable to those grown in nature. It is noticeable, however, that in these artificial cultures larger specimens were obtained than any which formed from the original material on horse-dung. In the former series several stromata measured 2.5 , or even 5 to $6 \mathrm{cms}$. in height, whilst in the latter none grew to more than $1.5 \mathrm{~cm}$.

It was frequently remarked that if, in the transference of the cultures from one medium to another, a stroma was touched or injured in any way, rapid growth at once took place at the point of injury, and new stromata were quickly formed as lateral branches of the older one (cf. Fig. 5). At all points where growth is vigorous can be seen numerous drops of a pinkish or yellowish fluid; this occurs, not only before the formation of a stroma, but also from the disk-like surface of the fully formed stroma, at the time of the formation of perithecia and asci.

As these mature, the liquid drops dry up, and the black spots, indicative of the ripening perithecia, become visible. The copious exudation of liquid is a prelude to the formation of the perithecia and ascospores. The possibility of its having anything to do with the projection of the trichogyne-like hyphae referred to below cannot be denied, but, since no spermatia or fertilization could be discovered, it seems more probable that the process is rather comparable 
with the excretion of fluid drops so often seen in Fungi when spores are being initiated, e.g. in Pilobolus. The phenomenon seems to partake of the nature of root-pressure in higher plants, occurring as it does at a time when a considerable supply of food material would be required from the substratum; it is at present, however, without any adequate explanation.

The natural substratum being horse-dung, it is not improbable that cellulose, or some product of its fermentation, is utilized by the Fungus; hence the later stages in the cultivation of these stromata were carried out on cotton-wool, thoroughly soaked with an extract of horse-dung, since after several days' culture on gelatine this medium was completely liquefied. An agar medium proved much less suitable than cotton-wool, probably owing to the rapidity with which the former dried up; on the contrary, cultures transferred from agar to cotton-wool at once began to grow vigorously and to send up new stromata.

From the earliest stages these stromata appear to be strongly apogeotropic; after a month or six weeks it was found that growth was more rapid at a temperature ranging from $10^{\circ}-13^{\circ} \mathrm{C}$. than from $15^{\circ}-18^{\circ}$, and again, that increased aëration of the cultures led to increased development, both in respect to the strength of the stromata and to the rate of growth.

With regard to the effect of injury to any part of the Fungus, it may be mentioned that in every case, when any portion of a stroma was cut off, e. g. the apical part of the one to the extreme left of Fig. $4 e$, for purposes of investigation, the cut surface of the stalk invariably grew out and formed a new stroma, which frequently developed into a specimen as strong as, or even stronger, than the one cut off. (See Fig. $6, a-d$, which represents the development of the lefthand stroma of Fig. $4 e$, after the removal of the slightly swollen head.) 


\section{INTERNAL ANATOMy.}

For the study of the internal anatomy of Poronia punctata, specimens of stromata were chosen, of different ages, and grown both in an unsterilized medium, as found in nature, and in pure culture. These were hardened in various fixing solutions, e.g. Keiser's ${ }^{1}$ solution, absolute alcohol, Rath's, Flemming's ${ }^{2}$, and Hermann's ${ }^{2}$ solutions : of these the two last gave the most satisfactory results. The sections were stained with iron-alum, and haematoxylin, according to the method given by Heidenhain ${ }^{3}$. Many other methods of staining were tried, such as those employed by Dittrich ${ }^{4}$, Harper ${ }^{5}$, and Gjurasin ${ }^{6}$, but the haematoxylin stain in most cases proved the most convenient as well as the most useful.

As already mentioned, in the very earliest stages no differentiation can be seen in the hyphae composing the young stroma (Fig. 8). As soon, however, as the head begins to expand, there can be seen scattered amongst the hyphae of the middle and upper part of the stalk more deeply stainable hyphae, with swollen clavate ends, apparently filled with food material.

What the true nature and function of these hyphae may be, I am unable to say, but it seems significant, that whilst they are very abundant in the lower central and especially in the marginal portions of still further developed stromata, which show young stages in the formation of perithecia, they are apparently not to be found either in old specimens with ripe perithecia or in mature stromata which have formed conidia only and as yet no perithecia. In this connexion compare Figures $\mathrm{I} 7, \mathrm{I} 8,3 \mathrm{I}$, which represent sections of specimens grown,

1 See Dittrich, Zur Entwickelungsgeschichte der Helvellineen. Cohn's Beitr. viii, 1898 .

${ }^{2}$ Zimmermann, Microtechnique.

${ }^{3}$ See Dittrich, lot. cit 4 Ibid.

${ }^{5}$ Harper, Pringsh. Jahrb. xxix, xxx.

${ }^{6}$ Gjurasin, Ueber die Kerntheilung in den Schläuchen von Peziza vesiculosa, Ber. d. Deutsch. Bot. Ges. xi, I 893 . 
some under natural conditions and others in pure cultures, in captivity. The distribution, described above, of these swollen hyphae seems to indicate that they may possibly have some important connexion with the formation of perithecia, and they may indeed be genetically connected with the hyphae from which these arise. Moreover it is not impossible that at even this early stage in the development of perithecia some fusion of the contents of two different hyphae may have taken place; but it must be acknowledged that, in spite of a careful search over a large number of preparations, no proof of such a union could be found, although, as Fig. $18 b$ shows, the nucleus in the swollen apical cell of the hyphae is of an unusually large size.

These hyphae present a striking resemblance to the deeply stained hyphae figured by Marshall Ward ${ }^{1}$ in Stereum hirsutum, and also to the very young ascogenous hyphae described by $\mathrm{Krabbe}^{2}$ in Cladonia stellata, though in this latter case they are related to one ascus only and not to a whole apothecium.

Similar early stages in the formation of ascogenous hyphae have been figured by Dittrich ${ }^{3}$ in Mitrula phalloides. There is also the possibility that these clavate hyphae are members of a system of conducting tissue such as that described by Istvanff ${ }^{4}$ in some species of Stereum and Radulum.

If sections of a slightly older stroma than that shown in Fig. I 7 be examined, it will be seen that from the outermost layers of hyphae numerous conidia have been formed, giving rise to a thick covering of spores over the top and sides of the swollen portion of the head. This reminds us of the behaviour of the stromata of the closely related Xylaria ${ }^{5}$, and indeed of many other Ascomycetes, Nectria, Claviceps, \&c., which always produce crops of superficial conidia before the

${ }^{1}$ Marshall Ward, Phil. Trans., vol. clxxxix, 1897.

${ }^{2}$ Krabbe; cf. Von Tavel, Vergleichende Morphologie der Pilze, I892, Fig. 3 I.

3 Dittrich, Cohn's Beiträge, viii, I 898, Figs. I, 5,7 .

- Istvanffi, Bot. Centralbl., I887 ; Prings. Jahrb., I 896.

${ }^{5}$ Cf. De Bary, Comp. Morph. Fungi, p. 244. 
perithecia, also of Marshall Ward's ${ }^{1}$ discovery that the somewhat similarly shaped stromata of Onygena produce chlamydospores on the surface before the asci are developed inside.

At different levels below the surface of the stroma of Poronia are visible circular knots of hyphae, distinguished from the surrounding hyphae by their smaller diameter and by their staining more readily. Within these knots of hyphae are seen much larger and still more deeply stained portions of a coiled hypha, which is, in fact, the 'Woronin's hypha' described by Fuisting ${ }^{2}$ in Polystigma as well as in Xylaria and other members of this group (e.g. Figs. 16, 20, 21). The width of this hypha in Poronia punctata is $4 \cdot 4 \mu$. Further sections showed portions of this hypha passing up from below through the vegetative parts of the stroma into the coil, and in very occasional instances this was seen after it had formed one or two turns in the coil, but before it had become invested by the surrounding knot of hyphae (cf. Figs. 27, I9, $a$ and $b$ ).

After the formation of the coiled row of cells this hyphae grows on beyond the coil towards the surface of the stroma (Figs. 20, 2I). This portion, however, is always more slender than the cells forming the coil, and though in several instances it was seen running right up to the surface, reminding one of the trichogyne of Collema, Physcia, or Polystigma, no evidence could be obtained that it functions as such.

Although hundreds of serial preparations were examined, in no case was a section found which showed the hypha through the whole of its course, indeed it was rare to find the portions growing towards the knots shown in the same stroma, whose sections showed several instances of the 'trichogyne' process. This would suggest that the lower portion quickly disappears, or is emptied of its contents after the early stages of the perithecium are completed. In addition to the deeply stained knots of hyphae enclosing the Woronin's

${ }^{1}$ Marshall Ward, Onygena equina, Willd,, a Horn-destroying Fungus. Phil. Trans., vol. cxci, I899.

${ }^{2}$ Fuisting, Zur Entwickelungsgeschichte der Pyrenomyceten. Bot. Ztg., I867I868. 
coil, may be seen numerous other groups of hyphae, of a similar character, but apparently empty and somewhat less closely interwoven. These probably represent one of two things :- $(a)$ very young stages of perithecia before the formation of Woronin's hypha; or, (b) abortive perithecia, which will never come to maturity.

Having regard to the large number of young stages always present in young stromata, compared with the number of mature perithecia scattered over ripe stromata, it seems very probable that very many such coils are abortive, possibly owing to lack of food-material for the formation of such large numbers of perithecia and asci, the competition of the successful perithecia, which attract all the supplies, being too much for them.

On the other hand, the question arises whether the coil always develops from a definite hypha, which grows up from the main body of the stroma, and after coiling up continues its growth on towards the surface, and as a result of this coiling the neighbouring hyphae grow round and invest it-as seems to be the case-or whether the knot of smaller hyphae is sometimes at any rate formed first, and the Woronin's coil developed within this afterwards.

By more active growth of the investing hyphae on the upper side of the Woronin's coil, the young perithecium gradually loses its circular form and becomes pear-shaped. At this stage the coil is still apparent (Fig. 21), but as the upper part of the perithecium becomes more and more enlarged, the coil appears to be broken up into its component cells, and ere long we find a stage in which the body has become quite pear-shaped, though still lying some distance below the surface, and has the narrower upper portion lined with delicate undivided hyphae-the periphyses-whilst at the base is a group of stouter deeply stained hyphae, presumably the remains of the coil, and now representing the young ascogenous hyphae (Fig. 23). By the continued growth of the lateral hyphae of the perithecial wall, possibly aided by the solvent action of some of them, a cavity is produced 
in the middle, and the lateral hyphae gradually grow up through the stroma towards the surface, whilst from the base and sides of the swollen lower portions numerous septate filiform hyphae-the paraphyses-arise; these grow up between the ascogenous hyphae, and fill the cavity of the perithecium. The stouter ascogenous hyphae are still seen at the base, and in larger numbers than before; these, apparently by branching, give rise to the asci, which eventually line the perithecium in great numbers (cf. Figs. 24-26). The complicated nature of the perithecium at this stage, its thick wall and dense mass of paraphyses, make this point very difficult to demonstrate clearly, but a comparison of the stages observed in Poronia with those figured by Fisch ${ }^{1}$ in Polystigma and Xylaria, makes it probable that the course of events is as described above.

The mature perithecium consists of a very definite wall of closely interwoven hyphae lined with a smaller-celled hymenial layer, whence arise the very numerous club-shaped asci, intermingled with numerous paraphyses. The somewhat long neck, which opens by an ostiole to the exterior, is lined by delicate periphyses, which more or less completely fill the cavity leading into the perithecium (Fig. 26).

It has been pointed out to me by Professor Marshall Ward that the observations at this stage suggest the possibility that the trichogyne-like hypha referred to above may be a sort of pioneer hypha to prepare the ostiole, and that it starts the dissolution of the surrounding hyphae and so prepares the passage.

A somewhat similar theory to the above was propounded in 1888 by Lindau ${ }^{2}$, in reference to the trichogynes developed by various Lichen-forming Fungi. At that time he regarded the trichogyne as partly sexual and partly mechanical in its function, but in $1899^{3}$ he denied to the trichogyne, in the cases investigated by him, any sexual function, and described

\footnotetext{
${ }^{1}$ Fisch, Beiträge zur Entwickelungsgeschichte einiger Ascomyceten. Bot. Ztg., 1882 .

${ }^{2}$ Lindau, Ueber die Anlage und Entw. einiger Flechtenapothecien. Flora, I 888.

${ }^{3}$ See Darbishire, Pringsh. Jahrb. xxxiv, Heft 2, p. 330.
} 
it as a purely mechanical organ, which bores through the overlying tissues, preparatory to the subsequent growth of the paraphyses of the developing apothecium.

Darbishire ${ }^{1}$, in his recent work on Physcia pulverulenta, rejects Lindau's view for that Lichen, mainly upon the grounds of the unsuitable structural character of the trichogyne as a boring organ, and of the relative positions of the organic apex of the young apothecium and the line of growth of the trichogyne. These, he points out, are most frequently in quite different vertical planes, and therefore the trichogyne cannot prepare the way for the growth of the paraphyses, which he regards as the true boring or dissolving organs. Whilst on the one hand this objection of the relative position of trichogyne and perithecium will not hold in Poronia, on the other hand it seems impossible to relegate to the organ any function as an 'organ of conception,' for, in the first place, no trace of spermogonia with spermatia has been found in this Fungus, and in the second place, the only other form of spore which occurs besides the ascospores is that of the conidia which precede the ascospores, and which germinate readily, producing a cycle of development quite indistinguishable from that resulting from the germination of an ascospore. Hence, if the trichogyne-like process in Poronia is rightly regarded as the homologue of the similar organ occurring in the Florideae and the Collemaceae-and this seems the only tenable view-we may, so far as concerns its relation to a fertilization-process, regard it as a degenerate organ, reminding us of the functionless fertilization-tubes formed by the antheridia of some species of the Saprolegnieae. It would then be quite intelligible, if, having lost this sexual function, the organ should become more mechanical in its action. Undoubtedly (as Darbishire contends for Physcia pulverulenta) in Poronia the chief part of the work of boring through or dissolving the overlying hyphae is performed by the hyphae forming the lateral wall and the periphyses, but

${ }^{1}$ See Darbishire, Ueber die Apothecienentwickelung der Flechte Physcia pulverulenta. Pringsh. Jahrb. xxxiv, Heft 2. 
it is conceivable that in their growth they follow a path already prepared for them, by the trichogyne-like hypha.

The Asci in their youngest stages are small club-shaped bodies with very abundant finely granular protoplasm, especially dense in the apical region, near which lies the large nucleus. The ascus gradually elongates; the nucleus divides into two, four, and then eight, and around these the protoplasm aggregates. As described by Harper ${ }^{1}$ in various Ascomycetes, the ascospores arise by free cell-formation, some protoplasm being left over as an 'epiplasmic' layer, lining the wall of the ascus. This author regards such a mode of development as strong evidence against any close relationship between asci and sporangia (in which spore formation is by cleavage of the protoplasm, proceeding inwards from the sporangium walls), such as Brefeld's theory requires.

In spite of numerous trials, I have failed to get perfectly satisfactory karyokinetic figures in the division of the nucleus in the ascus, owing to difficulties in fixing and staining, but sufficiently convincing examples have been seen to show that two and then four nuclei are present, and that later each spore contains one nucleus. In the stage with the eight naked masses of protoplasm the free nuclei were not however clearly seen. The eight spores finally come to lie in a single row, each surrounded by a double wall, the outer of which, on ripening, becomes dark brown in colour, with a clearly marked lateral slit-like pit ${ }^{2}$ (Figs. $28-30$ ). When first liberated from the ascus, the elliptical spores are surrounded by a distinct gelatinous covering, resembling a halo. At the apex of the ascus the wall is seen to be folded in, causing the 'epiplasm' to form three peg-like projections, like those represented by Zopf in Hypocopra ${ }^{3}$. These are particularly obvious in the younger asci.

The Conidia, as already indicated, arise by abstriction from the ends and sides of the terminal hyphae of the stromata.

1 Harper, Cell-division in Sporangia and Asci. Ann. of Bot., Dec., 1899.

2 This lateral marking has been omitted by Brefeld in his figure of these ascospores, suggesting that his drawing may have been made from the other side of the ascus. Heft $x$, Taf. ix, Fig. 8.

${ }^{3}$ Zopf, Die Pilze, p. 92, Fig. 60. 
The conidium-forming hyphae are divided into very small cells by numerous septa, and they tend to break down into these component cells, and as a result this layer of hyphae falls away during the formation of perithecia (Figs. $3^{1}, 3^{2}$ ). This phenomenon was pointed out by Tulasne, Brefeld ${ }^{1}$, and Von Tavel ${ }^{2}$.

If sections of stromata of Poronia of various ages be treated with strong potash at $160^{\circ} \mathrm{C}$. and stained with iodine and sulphuric acid, in the manner described by Wisselingh ${ }^{3}$, it is seen that the walls of the hyphae all contain chitin, with the possible exception of the outermost rind-like layer, which retains its original brown colouration.

After a study of the internal anatomy of Poronia punctata, one is perhaps most struck by its many points of resemblance with Polystigma rubrum and P. fulvum; this is of course especially noticeable in the form of the archicarp, which in Polystigma consists of 'a long coiled row of many cells,' one extremity of which projects above the surface as a trichogyne. The coil appears to divide up into portions, which, after distribution over the hypothecium, branch to form the ascogenous hyphae. The marked point of difference between the two genera is the formation in Polystigma of spermogonia with spermatia, whilst in Poronia degeneration or development, as the case may be, has resulted in the entire absence of these bodies. In Polystigma, however, the union of spermatia with the trichogyne has not yet been observed.

It should be pointed out in this connexion, that although, in Poronia, perithecia with ripe asci have been formed on stromata grown in captivity, yet the number of perithecia developed was smaller than in those stromata which had reached the stage of immature ascospores before the material was brought into the laboratory. Also, whilst the former took at least one month to form asci, in the latter specimens the spores ripened in a few days. We are, of course, unable to say how long is required for the earlier stages in the

${ }^{1}$ See Brefeld, 1. c., Heft x, p. 261.

${ }^{2}$ Von Tavel, Vergleichende Morphologie der Pilze, p. 92. Jena, I892.

3 Wisselingh, Pringsh. Jahrb., I 898. 
formation of perithecia in nature. $U p$ to the present, in stromata grown in pure cultures, only the very early stages have been observed, i. e. the small-celled knot of hyphae, enclosing the coiled Woronin's hypha, although several specimens are more than two months old, and have been supplied with free access of air, and grown under varied conditions of illumination and temperature. Possibly the time of year is the explanation of this check in the development, and the asci are by some special adaptation of the Fungus only capable of being formed in the autumn months. This point can naturally only be decided by a further continuation of the cultures throughout the coming year. Whatever may be the true explanation of the details in the formation of the perithecia of Poronia, it seems clear that in this genus we have a very interesting example of Fungi with a Woronin's hypha, which as De Bary has already pointed out ${ }^{1}$ form a connecting link between the archicarps of Collema and Polystigma and the sporocarps of Claviceps. If we therefore regard these archicarps on the one hand as the homologues of the Woronin's hyphae on the other hand, we can give the position of Poronia as intermediate between Polystigma and Xylaria. In Polystigma the stroma is a somewhat less defined structure than in Poronia ${ }^{2}$, i. e. it consists of a fleshy cushion-like mass of tissue on the surface of the infected leaf, and in this mass the perithecia are embedded, whilst on the contrary the stromata of Xylaria are still more definite, more elaborate and horny structures than in Poronia.

This suggested position of Poronia is illustrated by a comparison of the details of the archicarp and its homologue and by the consideration of any other reproductive bodies which are formed in the respective genera; thus :-

In Collema we find a coiled archicarp with a prominent trichogyne, which penetrates to the outer surface of the thallus, and there fuses with the spermatia, which are formed in

1 De Bary, loc. cit., p. 236.

2 Cooke, Handbook of British Fungi, p. 803 . 
definite organs, the spermogonia - that is, in this genus, there is a clearly marked sexual act. These facts have recently been confirmed by Bauer ${ }^{1}$.

In Polystigma, a similar coiled archicarp with a trichogyne is present. Here, too, are found spermogonia with spermatia, which were seen by Fisch ${ }^{2}$ adhering to the trichogyne, but the union of the two was not observed.

In Poronia, we again find a coiled hypha (quite comparable to the archicarp of Polystigma), with a more or less degenerate trichogyne-process. In this genus, however, the spermogonia with spermatia are not developed, so that there can be no question of the sexual function of the trichogyne.

In Xylaria, this functionless trichogyne appears to have been dispensed with, as well as the spermogonia and spermatia. If this series of forms, and the implied homology of the organs in question be a correct view of the case, we must regard the ascospores of Poronia as formed parthenogenetically by intermediate stages from an organ, which represents the archicarp, which in certain other forms is sexually functional, but which in Poronia has lost that power. If further details of the stages between the coiled Woronin's hypha and the ripe asci could be determined, it is conceivable that later fusions of nuclei might be found to occur, which might be regarded as a secondary sexual act replacing the more obvious one, which has been lost in the earlier stage. This, presumably, would accord with Dangeard's ${ }^{3}$ view, that the fusion of the two original nuclei in the young ascus represents the true sexual act in the various Ascomycetes, which he investigated ${ }^{4}$. No such fusions have been seen, however, in Poronia.

The Botanical Laboratory, Cambridge, March, 1900.

${ }^{1}$ Bauer, Zur Frage nach der Sexualität der Collemaceen, Ber. d. Deutsch. Bot. Ges., vol. xvi, 1898 .

${ }^{2}$ Fisch, loc. cit.

${ }^{3}$ For a full discussion of the views of Harper and Dangeard upon the Sexuality of the Ascomycetes, see Wager, On the Sexuality of the Fungi, Ann. of Bot. xiii, Dec., I899.

'See Dittrich, Cohn's Beiträge, viii, 1898 . 


\title{
EXPLANATION OF FIGURES IN PLATES XIV AND XV.
}

\author{
Illustrating Miss Dawson's paper on Poronia punctata.
}

\section{PLATE XIV.}

Fig. I. Stromata of Poronia punctata from nature. $a$, stromata-stalks embedded in the substratum; $b$, stromata raised above the substratum.

Fig. 2. Group of individual stromata of different types, drawn from nature.

Fig. 3. Series of stages of growth of a group of stromata, cultivated in a pure state from an ascospore, on horse-dung extract in gelatine and agar. Ascospore sown on Nov. 4. $a=$ Nov. $23 ; b=$ Nov. $27 ; c=$ Nov. $29 ; d=$ Dec. I ; $e=$ Dec 5 ; $f=$ Dec. $8 . \quad$ T. $=15^{\circ}$ C. (Nat. size.)

Fig. 4. Stages in growth of stromata with disk-shaped heads, from germinating ascospore, sown Nov. I $8 . a=$ Nov. $28 ; b=$ Dec. $3 ; c$ and $d=$ Dec. II, showing two portions of culture, drawn separately; $e=\mathrm{Jan}$. I 7 . This culture transferred from gelatine medium to cotton-wool on Nov. 28. (Nat. size.)

Fig. 5. Branched stroma, grown in pure culture, on cotton-wool medium, from conidium germinated in gelatine medium. This stroma formed in eight days, after the culture was aërated and kept in the light. $T_{.}=17^{\circ}$. (Nat. size.)

Fig. 6. Proliferation of head of stroma, after apex has been cut off. $a=$ Feb. 23; $b=$ Feb. $26 ; c=$ Mar. I $; d=$ Mar. $5 . \mathrm{T} .=10^{\circ}-15^{\circ} \mathrm{C}$. (This represents later stages in the development of the stroma to the extreme left of Fig. $4 e_{\text {.) }}$ (Nat. size.)

Fig. 7. Two unusually large stromata grown up on culture drawn in Fig. $4 e$, after increased aëration and lower temperature. Age, Jan. I7-Feb. 26. T.= $10^{\circ}-12{ }^{\circ} \mathrm{C}$. (Nat. size.)

Fig. 8. Low power drawing of individual young stroma, as shown in Fig. $3 a$, nineteen days after sowing of ascospore. Horizontal mycelium flattened parallel to erect stroma, crystals of calcium oxalate in substratum. ( $X$ I 2.)

Fig. 9. Crystals (Fig. 8) under obj. $\frac{1}{6}$.

Fig. Io. Portion of mycelium grown from conidium in hanging drop culture. Separation of crystals from substratum. Eleven days old. ( $x$ I 80.$)$

Fig. II. Different methods of germination of conidia in gelatine, with horse-dung extract. $(\times 350$. $)$

Fig. I 2. Consecutive stages in germination of conidium in hanging drop. $a$, Nov. 7, I p.m.; $b$, Nov. 8 , I0.30 a.m.; $c$, Nov. 9 , 10 a.m; $d$, Nov. Io, I0 a.m. ; $e$, Nov. IO, 3 p.m.; $f$, Nov. II, IO a.m.; $g$, Nov. I2, 8.45 a.m.

Fig. I3. Consecutive stages in germination of ascospore in hanging drop. Medium = gelatine with horse-dung extract. $a=$ Nov. IO-I $2 ; b=$ Nov. I 3 , II a.m., t. $=\mathrm{I} 7^{\circ} ; c, 2.30$ p.m., t. $=\mathrm{I} 8^{\circ} ; d$, 5.15 p.m., t. $=\mathrm{I} 7^{\circ} ; e$, 7.IO p.m., t. $=$ I $7^{\circ}, 5 ; f$, IO.I 5 p.m., t. $=18^{\circ}, 5 ; g$, II. 30 p.m., t. $=18^{\circ}, 5 ; h$, Nov. I 4, I 2.30 a.m., t. $=18^{\circ}, 5 . \quad\left(\times 35^{\circ}.\right)$

Fig. I4. Mycelium from spore, shown in Fig. 13; Nov. 14, 10.30 a.m., t. $=17^{\circ}$. ( $x$ I00.) 


\section{Dareson.-On Biology of Poronia punctata (L.).}

Fig. ${ }_{5}, a$ and $b$. Portions of mycelium grown from ascospore (Fig. 13) showing cross-connexions of hyphae. Nov. I4, II a.m. (x I80.)

\section{PLATE XV.}

Fig. 16. Portion of head of stroma, showing perithecia in various positions, and of different ages. $(\times 90$.

Fig. 17. Young stroma taken from extreme left of culture, shown in Fig. 4, e. Hardened in Hermann's solution. Stained with Rubin S. Deeply stained, swollen hyphae below apical regions. ( $x$ 20.)

Fig. 18. Deeply stained swollen hyphae in stroma of age represented in Fig. I6. These hyphae especially abundant in outer regions of stroma. $a$ ( $\left.\times \mathrm{I}_{50}\right)$; $b$ ( $x$ I260.)

Fig. 19. First stages in coiled Woronin's hypha, before growth of investing hyphae. $a(\times 230) ; b(\times 340$.

Fig. 20. Perithecium showing Woronin's hypha, and trichogyne-process passing to exterior. Iron Alum, Haematoxylin. ( $x$ 230.)

Fig. 21. Two consecutive sections of same perithecium showing coiled hypha and trichogyne. Coil becoming broken up, and form of perithecium less spherical. $(\times 230$.)

Figs. 22-25. Stages in development of perithecium, showing formation of central cavity, periphyses, paraphyses and ascogenous hyphae. ( $x$ I 70 .)

Fig. 26. Mature perithecium, ostiole completely formed. Asci of different ages lining the hymenial layer. ( $x$ I 70.$)$

Fig. 27. Broad deeply stained hypha, grown up from amongst vegetative hyphae and coiled to form Woronin's hyphae. Surrounding investing hyphae smaller celled. Iron Alum, Haem. ( $x$ 680.)

Fig. 28. Group of asci, from perithecium hardened in Abs. Alc. Asci in dilute ammonium hydrate. ( $\times 300$.)

Fig. 29. Young asci separated out showing accompanying paraphyses. $(x 300$.

Fig. 30. Different stages in development of ascospores. $a$ and $b(\times 600)$; $c$ and $d(\times 400$.

Fig. 31. Stroma grown in pure culture. Conidial formation from terminal hyphae. No perithecia forming. ( $\times 40$.)

Fig. 32. Formation of conidia, breaking up of conidia-bearing hyphae. $(\times 330$.

Fig. 33. Group of fresh ascospores, showing lateral slit-like depression of exosporium. ( $\times 320$. 

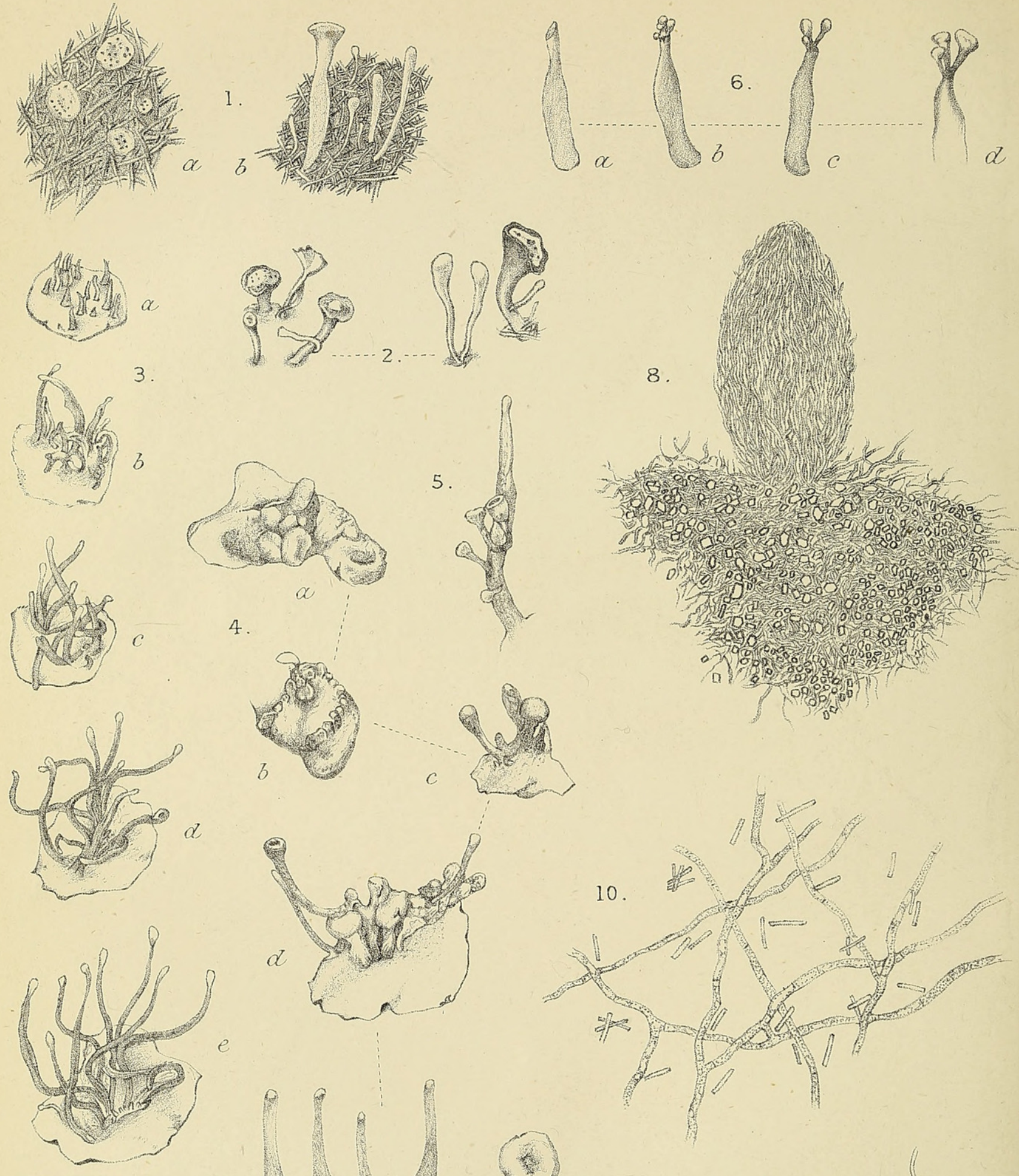

8.
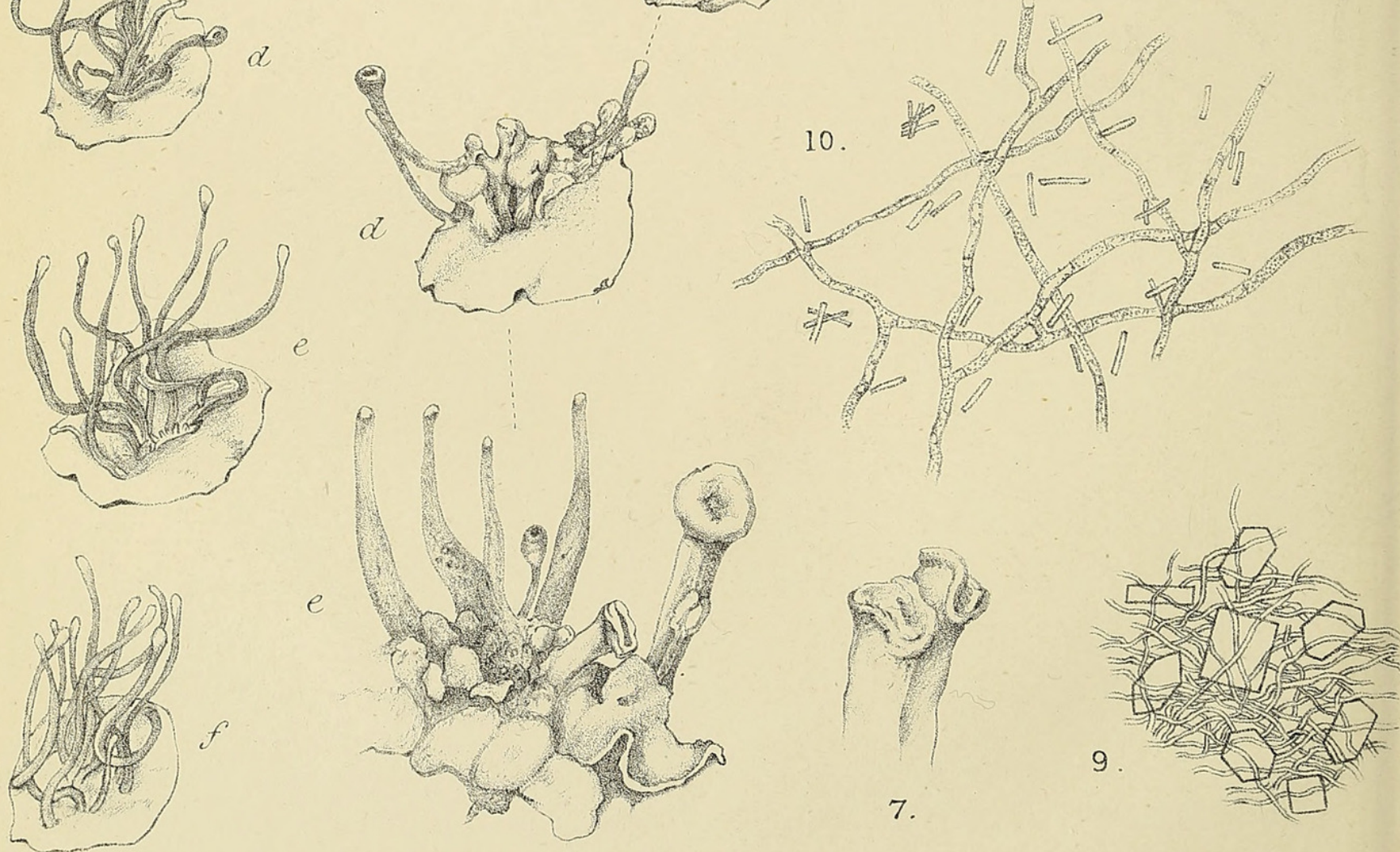

M.D. de 1 . 


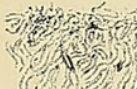

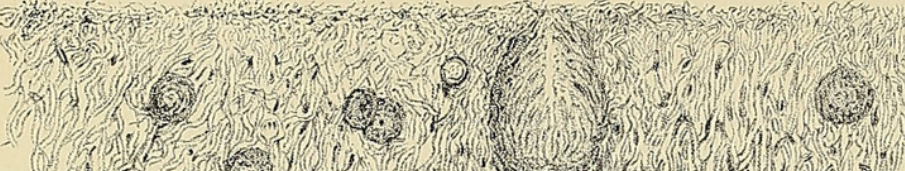

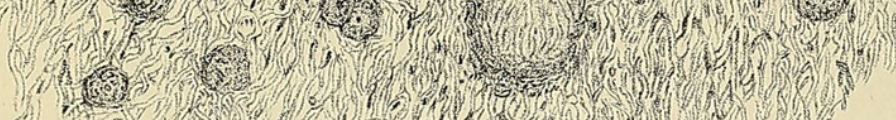

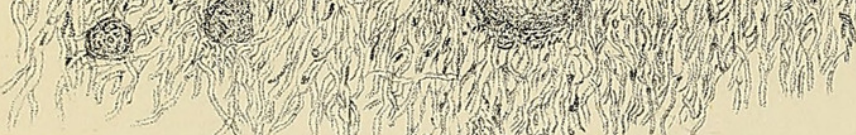

16. X.1. (n)
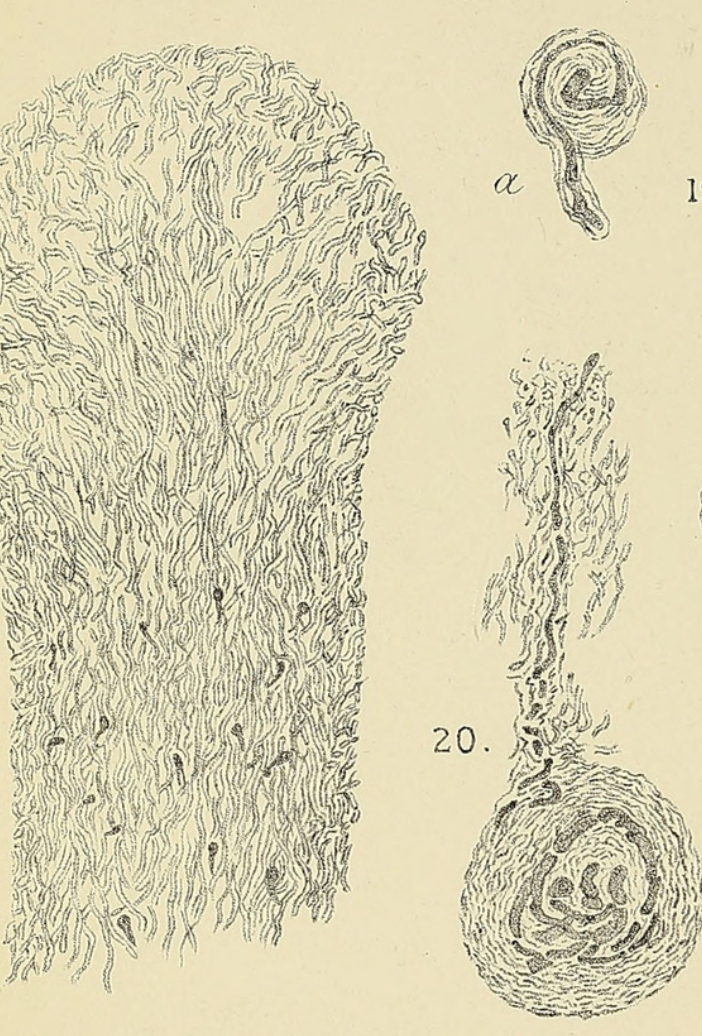

9.
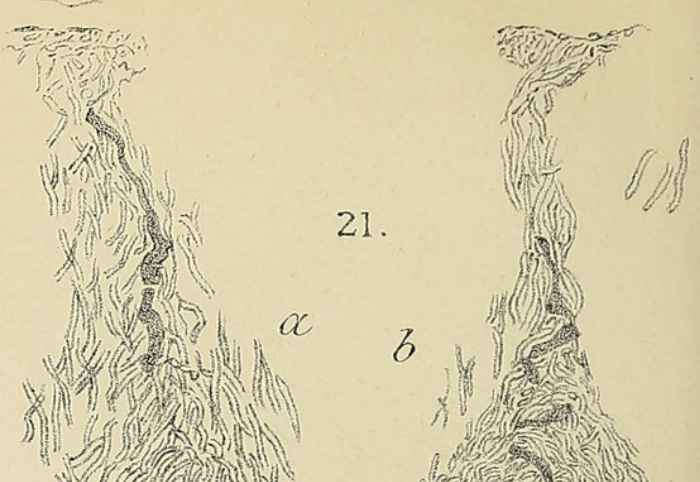

(a) (n) no

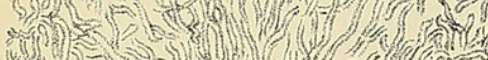

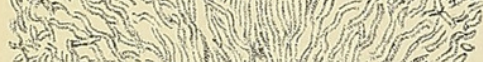

son.

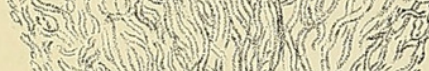
nont ind (c) (2)

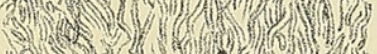
us 5. 15 ( ) 3. (5) (1) E)

17. (-) No (o) yofor. a) ing (o)

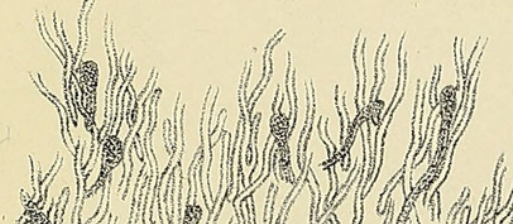

$$
\text { (1.) }
$$


1.). (3)

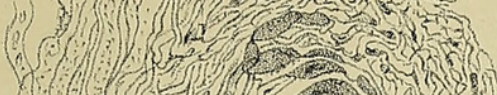

1.)

$7 \%$. 5 .

$6(162)$

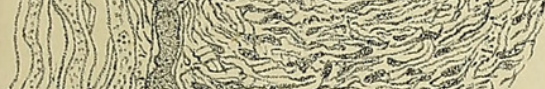

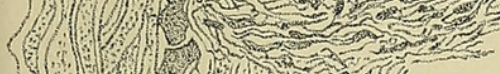

3. (1) 5 (2) (1) (1) 0 1.

(2)
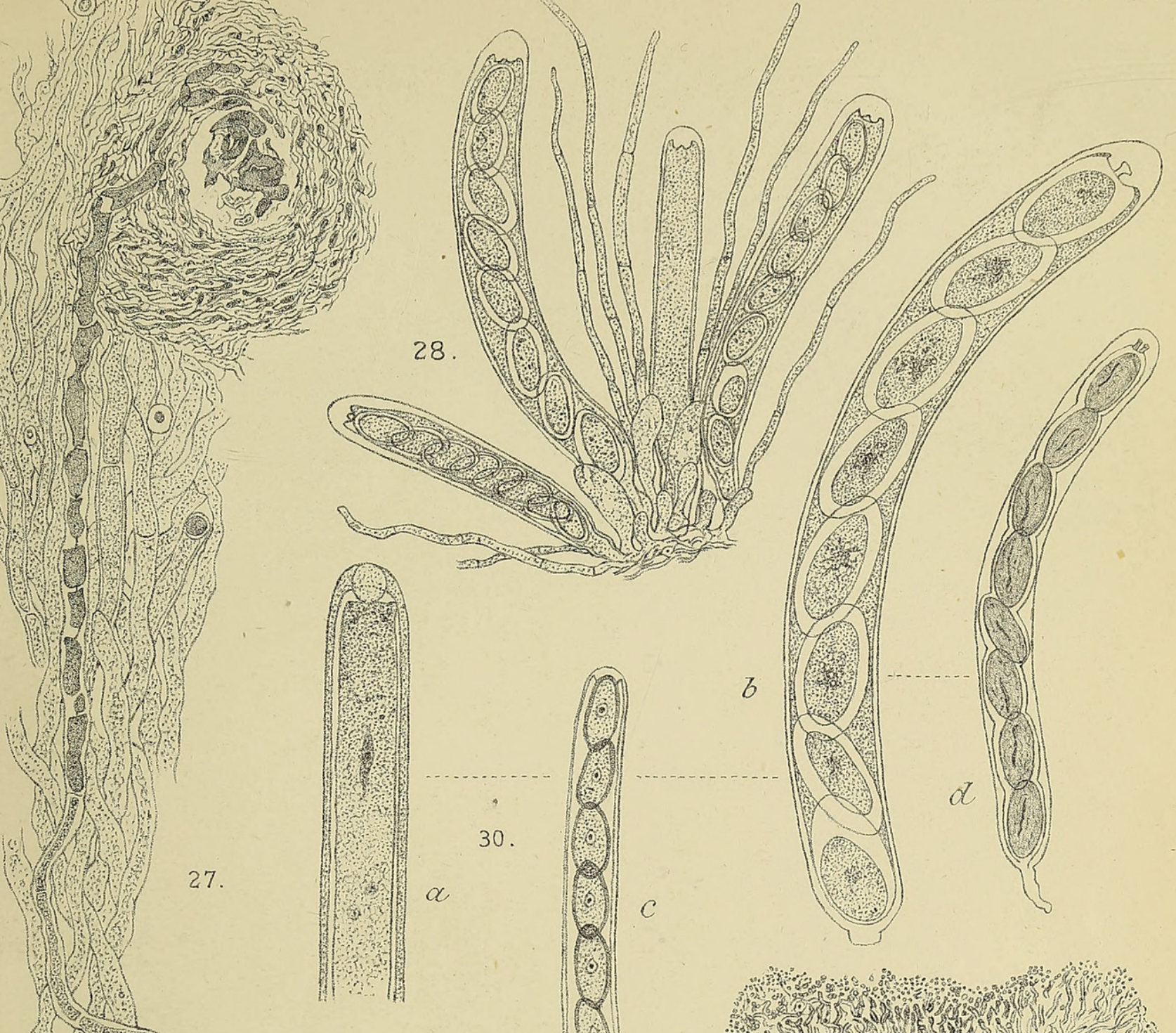
.
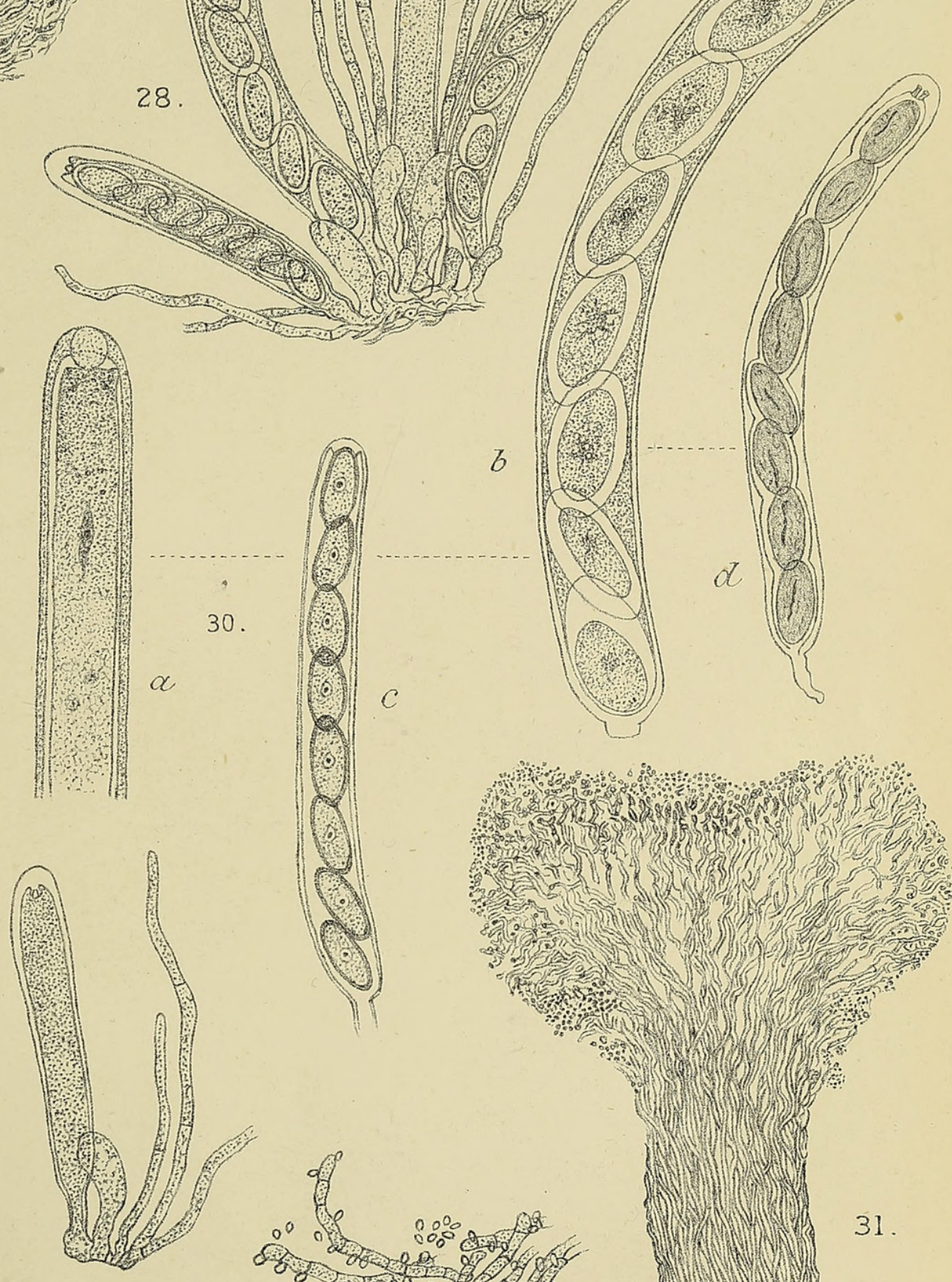

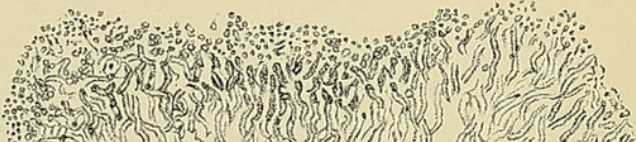
(6)

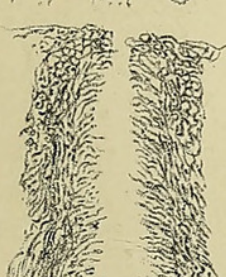

26.

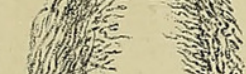

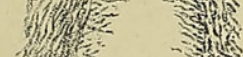

V)
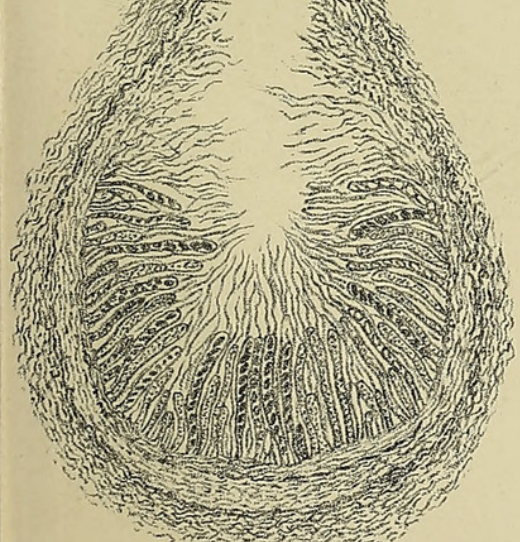
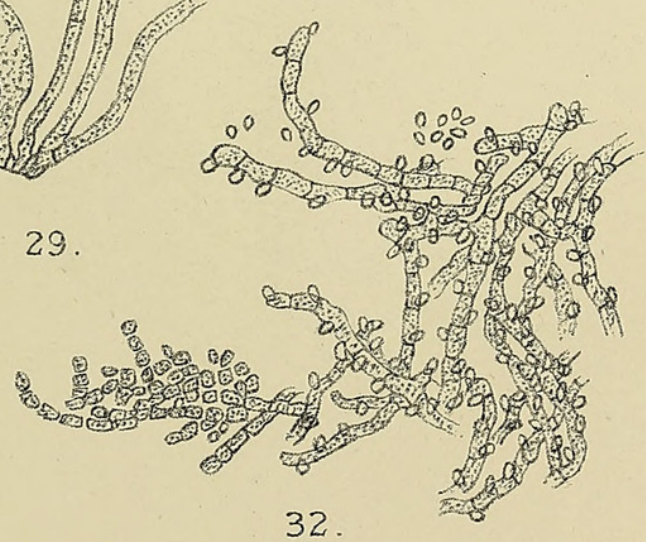

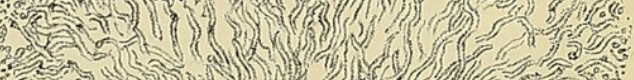

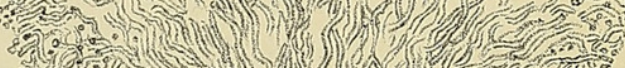
3. a *6. - $\rightarrow$ क in)

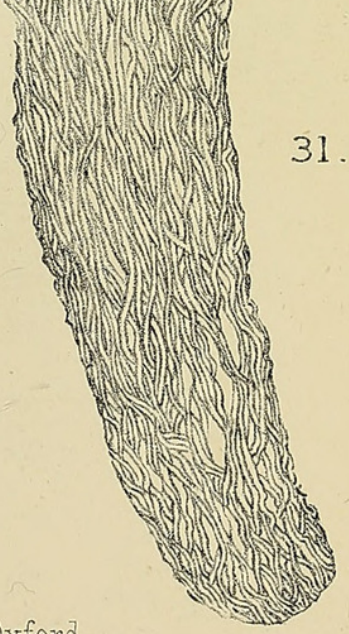




\section{$2 \mathrm{BHL}$ Biodiversity Heritage Library}

Dawson, Maria. 1900. "On the biology of Poronia punctata (L.)." Annals of botany 14, 245-262. https://doi.org/10.1093/oxfordjournals.aob.a088776.

View This Item Online: https://www.biodiversitylibrary.org/item/238259

DOI: https://doi.org/10.1093/oxfordjournals.aob.a088776

Permalink: https://www.biodiversitylibrary.org/partpdf/318583

\section{Holding Institution}

Smithsonian Libraries

\section{Sponsored by}

Biodiversity Heritage Library

\section{Copyright \& Reuse}

Copyright Status: Not in copyright. The BHL knows of no copyright restrictions on this item.

This document was created from content at the Biodiversity Heritage Library, the world's largest open access digital library for biodiversity literature and archives. Visit BHL at https://www.biodiversitylibrary.org. 